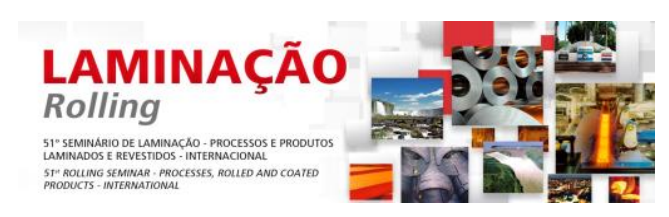

\title{
ESW'S RESEARCH AND DEVELOPMENT A COMBINATION OF TRIALS AND SIMULATION*
}

\begin{abstract}
In the past the research and development of new materials for hot mill rolls was mostly done by trials. Such trials are expensive and difficult to transform from small size to the big size of a solid roll. Computation is the cheaper way to get ideas processed and can be varied in different directions. The main part before simulation is the generation of the needed basic data of the specific materials. Some data is already well known and can be bought from databases; others have to be done specifically for our materials. The evaluation of such results has to be done still with solid trials, but the number of trials can be reduced. The advanced techniques of finite element calculation offer a wide range of possibilities to get answers about alloys, solidification, casting parameters and their influence. The possibility to calculate a heat treatment cycle and to get an answer about the internal stress modification during the cycle is a great help to understand the principle of transformation. Examples of different calculations in various fields will be given. The close cooperation with universities and other research institutes as well as the inhouse possibilities will be presented.
\end{abstract}

Keywords: R\&D process; R\&D system; R\&D management; R\&D trials; Simulation.

Quality Manager, ESW, Eisenwerk Sulzau-Werfen.

Vice President R\&D, ESW, Eisenwerk Sulzau-Werfen.

$R \& D, E S W$, Eisenwerk Sulzau-Werfen.

* Technical contribution to the $51^{\text {st }}$ Rolling Seminar - Processes, Rolled and Coated Products, October $28^{\text {th }}$ to $31^{\text {st }}, 2014$, Foz do lguaçu, PR, Brazil. 


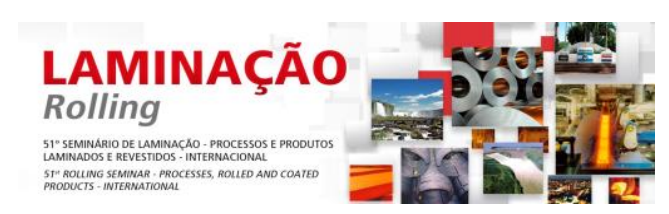

\section{R\&D MANAGEMENT}

\subsection{Definition of R\&D [1]}

Research $=\quad$ A systematic way of working to seek after new knowledge or new ideas WITH or WITHOUT a specified application in mind.

Development $=\quad$ A systematic way of working that USES the knowledge from research results, scientific knowledge or new ideas to produce

New Materials or noticeable improvements of already existing materials

Research is in practice very often a combination of research and development. The needed financial resources are more limited than in different other productions. The amount of real trials is in a much later stage and all research results and possibilities before casting a new roll are applied to save money and time.

In roll making the $R \& D$ expenditures are of course far away from medical companies that sometimes spend more than $25 \%$ of the TO. In the case of ESW this number corresponds to around $2 \%$.

R\&D management is the process and technique used to control the amount of money and effort invested in research and development (R\&D) projects.

\subsection{The Goals of the Roll Makers R\&D Efforts}

As a roll maker we are supposed to develop the roll material in several directions. The key problems to be avoided are:

1. wear

2. cracks

3. breakages

5. problems in grinding and testing

5. etc.

In essence this means that we are supposed to increase the life of the roll without influencing negatively neither the quality of the rolled product nor the behaviour of the mill. As one can easily understand this is not always a simple task even though it may appear as a rather limited activity.

\subsection{How to Decide what should be a R\&D Project}

The most difficult aspect regarding the majority of the R\&D activities is to define:

1. What to do?

2. Why to do it?

3. When to do it?

4. How long time will it take?

5. How much money will it cost?

There are normally two questions that must be answered prior to starting any activities. The first one is related to the outside of ESW in the direction of our customers where the competitors are and where we are ourselves. The second one is what part of our process is more related to learning by doing and would need deeper understanding. The result of the 2 questions should give the answer if there is a need to change and to improve or not.

Several important inputs are to be used in this decision making of what and why to do:

* Technical contribution to the $51^{\text {st }}$ Rolling Seminar - Processes, Rolled and Coated Products, October $28^{\text {th }}$ to $31^{\text {st }}, 2014$, Foz do Iguaçu, PR, Brazil. 


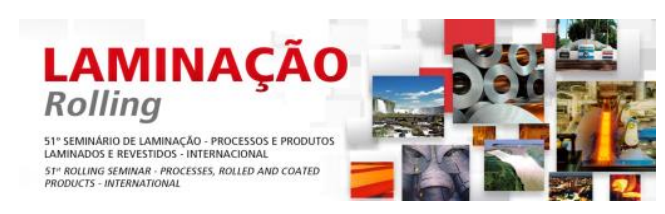

1. Customer requirements (known and unknown) - short term and long term

2. Product life cycle analysis

3. Own ideas

4. Company strategic decisions

5. Competitors activities

6. Etc.

The customer requirements are most often not directly declared. It is the (maybe poor) result of the roll in the mill that creates desire for improvement. Usually different performance between rolls of different suppliers is the first input to an activity or a new requirement. Sometimes the roll user can express requirements because of changes in the productivity or sizes and materials to be rolled in the future. It is not always the highest priority to increase the campaign length or the performance. Sometimes the requirement is just to reduce losses due to high incident rates in the mill. The required Mill flexibility regarding changing product range and gages creates high load to the rolls and the incident rate can go up. In this case High sensitive and high performing rolls are not a useful tool anymore.

The term product life cycle is used to determine the different stages that a product goes through. By studying a product's life cycle it is thus possible to evaluate the effectiveness of a product and the eventual need for a new product in a certain segment. One example of a life cycle curve is shown in figure 1 below.

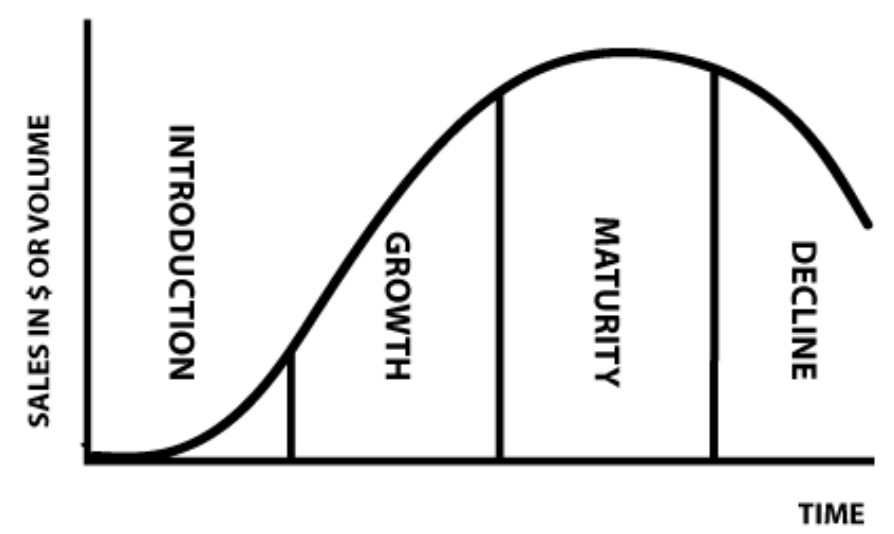

Figure 1. Principal sketch of a life cycle curve [2].

All products begin with the Introduction Stage that occurs when a product is first to be found on the market. Products then move to the Growth Stage (if not previously pulled out of the market) and must then be further developed and marketed. If a product proves to be accepted with our customers normally sooner or later other companies will begin to produce similar products.

The Maturity Stage is reached when the sales volume of a product begins to decline. In rare cases a product may gain a steady consumer acceptance e.g. Indefinite Chill rolls that is a more than 90 years old invention.

\subsection{R\&D - the Different Project Types - ESW Definition}

At ESW we are working with essentially 3 different categories of R\&D projects. They can be classified as described below:

1. Competence projects

2. Strategic projects

3. Development projects
(Classified as a $R$ project)

(Classified as a $R$ project)

(Classified as a D project)

* Technical contribution to the $51^{\text {st }}$ Rolling Seminar - Processes, Rolled and Coated Products, October $28^{\text {th }}$ to $31^{\text {st }}, 2014$, Foz do Iguaçu, PR, Brazil. 


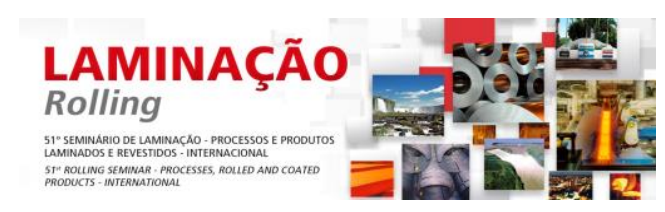

Figure 1 below describes these activities and how they interact. It is of course the ambition that the activities within the competence and strategic areas finally will lead to the development of a new product via the product development module.

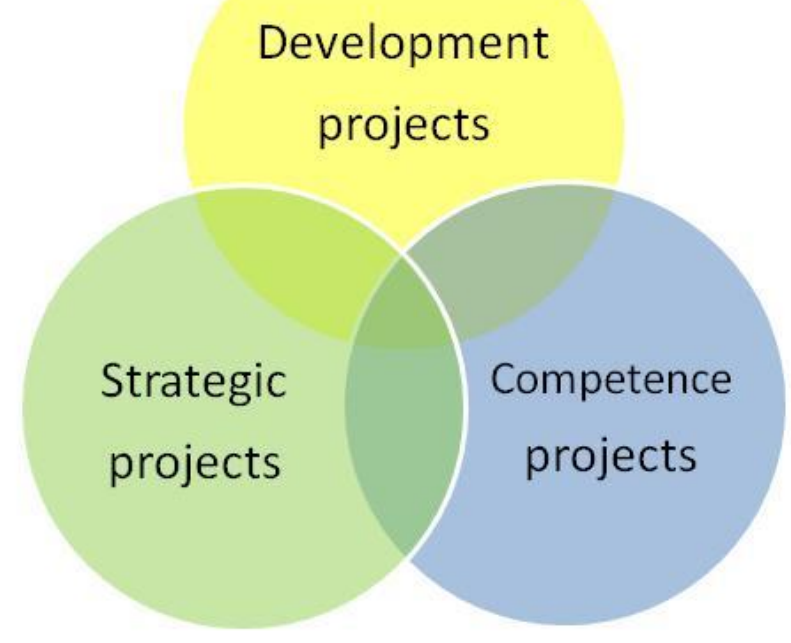

Figure 2. Different categories of R\&D projects [1].

\subsection{Competence Projects - ESW Definition}

With competence projects we define activities oriented to increase our basic scientific and technical understanding. These activities not necessarily are (but could be and very often are) directed to a specific product or problem.

Examples of projects/activities in this field are mentioned below:

- Simulation of Horizontal Centrifugal Casting

- Simulation of the static Core filling after spinning the shell

- Modelling of the Phase Transformation and Residual Stress in a Composite Mill Roll during heat treatment

- Welding a wear resistant coat on a roll

- Modelling for Life Cycle Analysis of HSM Work Rolls

\subsection{Strategic Projects - ESW Definition}

Activities with reference to products not yet sought after by the market BUT that have been judged by ESW to have a potential significance for the future. This in principal concerns both new materials and new processes not yet used (at least for roll making).

Examples of possible activities/projects in this field (to be also described later):

New materials:

Ceramic (SiALON)

Cemented Carbide

New processes:

Cladding

Spray forming (OSPREY)

Welding

PM HIP process

* Technical contribution to the 51st Rolling Seminar - Processes, Rolled and Coated Products, October $28^{\text {th }}$ to $31^{\text {st }}$, 2014, Foz do Iguaçu, PR, Brazil. 


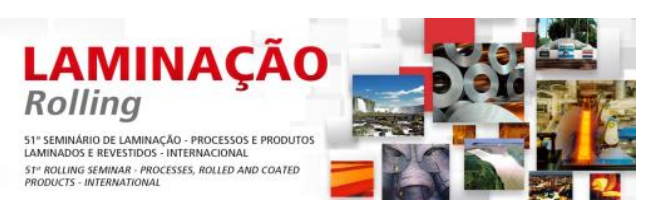

\subsection{Product Development Project - ESW Adaptation}

The development of new or modified products that have been identified as needed or sought for by our customers.

Modification in this respect very often means alteration of an existing product regarding its' chemical composition and/or the heat treatment.

This activity also includes testing of existing grades but for "new" applications - e.g. HSS rolls for the very last stands in the HSM finishing mill.

To facilitate the R\&D process there have been some modifications of the general description of the product development process. Figure 3 below is trying to visualize this in a schematic way.

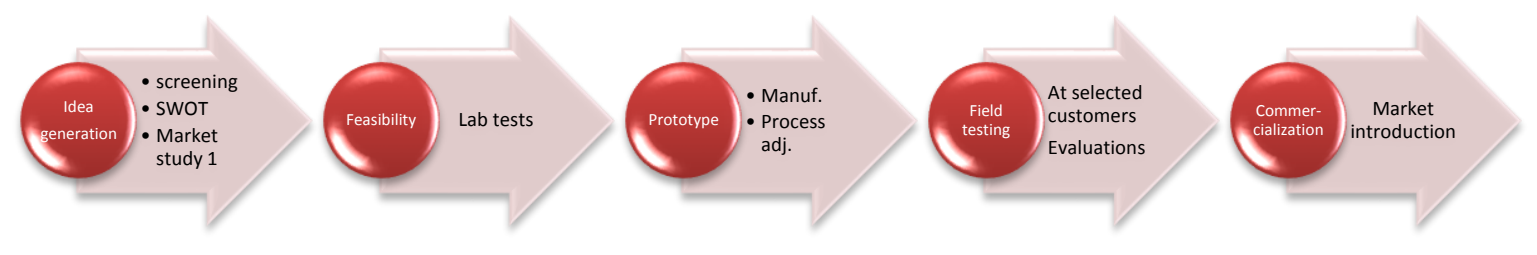

Figure 3. Schematic presentation of the ESW R\&D process [1]

\subsection{Transparent R\&D Process/System}

In addition to what has already been mentioned, see below some further comments why a R\&D (or other) management system needs to be transparent.

- To create a common goal throughout the company and increase the understanding of the importance of R\&D for long time survival.

- Identify resources needed to be successful in terms of:

- R\&D,

- Push for trials

- Follow up

- Marketing.

- Identify the "owner" of products to be developed.

- Facilitate the cooperation from production in terms of:

- "gold on floor"

- investments

- Clarify where R\&D costs should be allocated.

\section{R\&D EQUIPMENT TO SUPPORT THE R\&D PROCESS}

\subsection{Introduction}

It is of great importance that as much as possible of the needed R\&D work is done in house. Not only for the secrecy of some of the work but also for the speed of development. In this respect advanced R\&D equipment is essential for solving tasks.

\subsection{Fundamental R\&D Equipment}

Since $100 \%$ of the production at ESW is based on the centrifugal casting it is essential to have a pilot plant machine that can simulate that process.

Hereinafter a list of some of the most important R\&D equipment (or equipment that is used to support the R\&D work):

1. Laboratory melting equipment

* Technical contribution to the $51^{\text {st }}$ Rolling Seminar - Processes, Rolled and Coated Products, October $28^{\text {th }}$ to $31^{\text {st }}, 2014$, Foz do Iguaçu, PR, Brazil. 


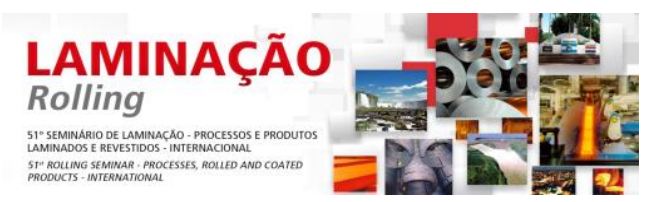

2. Thermal analysis

3. Metallographic laboratory

4. Chemical analysing equipment

5. Pilot casting machine

6. Cutting machines

7. Heat treatment furnaces

8. Mechanical testing (hardness and strength)

9. Dilatometer

10. Optical Microscopes

11. High speed video camera

12.SEM

13. Image analysing systems

14. Computer simulation programs for casting and solidification

15. Thermal imaging camera

16. Stress measurement equipment

17. Residual austenite measuring equipment

Below some photos showing several of the R\&D tools of ESW.
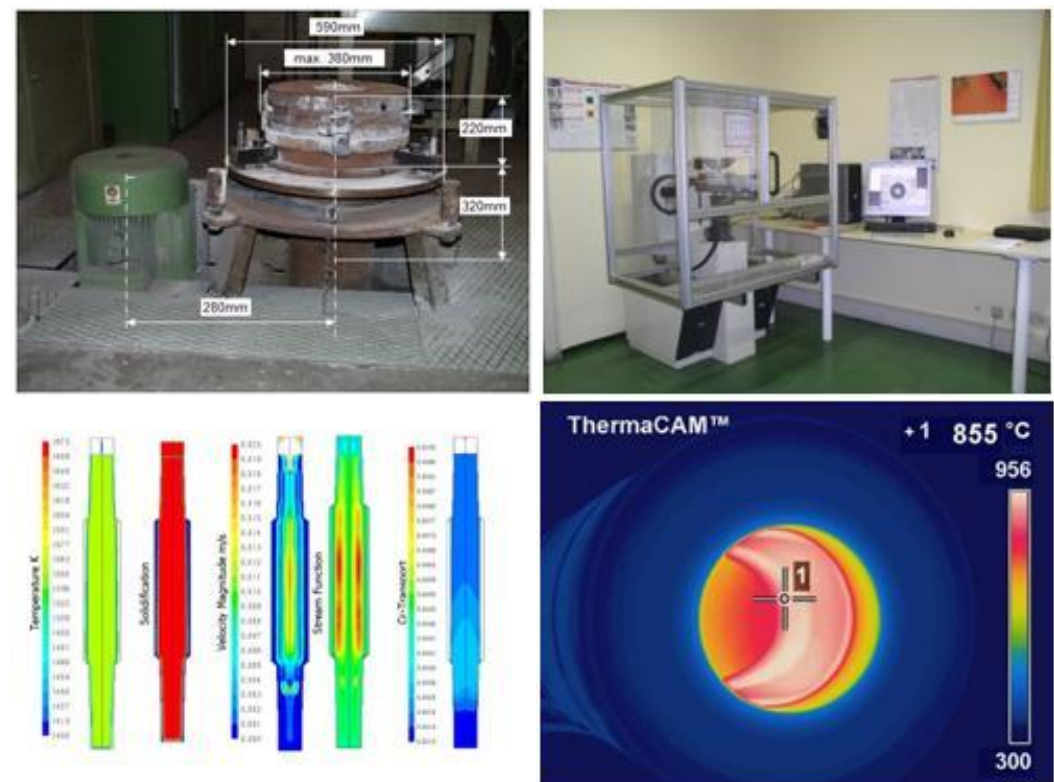

Figure 4. Spin casting pilot machine, Hardness tester, Computer simulation, Investigation with Thermal Imaging Camera.

\section{SOME EXAMPLES OF RECENT PROJECTS}

\subsection{Static Core Filling after Spinning the Shell Sleeve}

This project was carried out together with the institute for modelling and simulation of metallurgical processes at the "Montanuniversity of Leoben". At the institute the simulation was programmed in FLUENT and ESW made the experimental part and video studies. The goal of the project was to find out the most influencing parameters for the shell thickness after pouring the core metal. The variations were carried out with different shell temperatures, with different core temperatures and different casting speeds. As pouring nozzle from top a donut nozzle was used. The results could be verified with different material combinations of shell and core. Figure 5

* Technical contribution to the $51^{\text {st }}$ Rolling Seminar - Processes, Rolled and Coated Products, October $28^{\text {th }}$ to $31^{\text {st }}, 2014$, Foz do Iguaçu, PR, Brazil. 


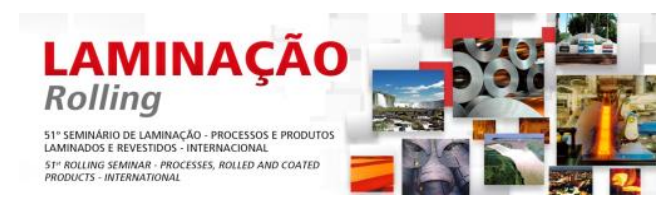

shows the practical trial at ESW with the open core stream recorded with a high speed video camera.

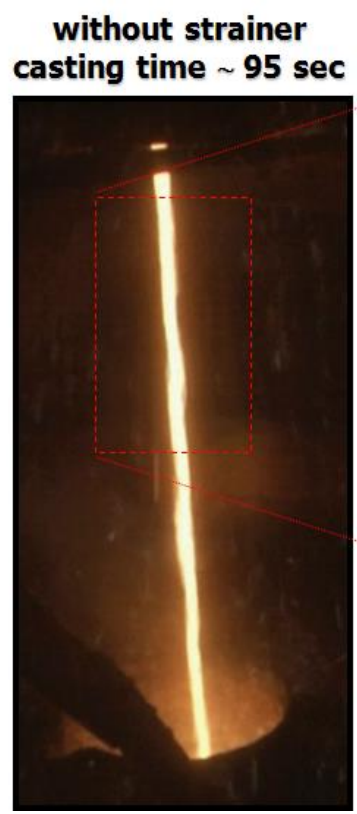

$10 \mathrm{t}$ core material $/ 1450^{\circ} \mathrm{C}$

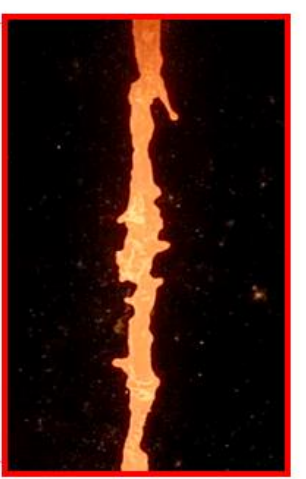

CASIO EXIUIM EX-F1 shutter time: $1 / 20000-300 \mathrm{fps}$

Figure 5: experimental trials of core filling

The left picture shows the casting stream without strainer in the downgate. The result is a very wide and rotating pouring stream. In the right picture we can see the same configuration with a strainer in the pouring cup. The stream is very narrow and no splashing is observed.

Figure 6 shows an example of the calculation in fluent, highlighting the vortex of the liquid melt falling down into the roll shell by top feeding.
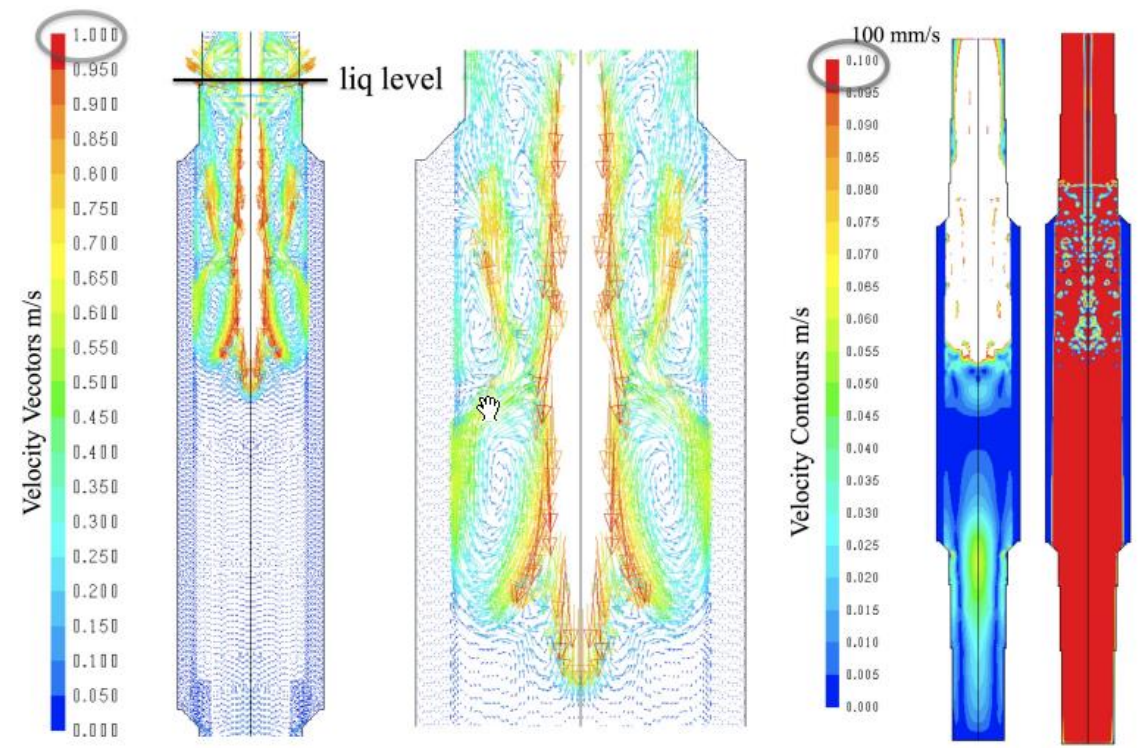

Figure 6: Simulation of core filling with speed vectors of vortex

The final report of this project gave a deeper understanding about the core filling process. The control of remelting of the shell into the core is since then easier to vary for different purposes such as varying dimensions and heights of the mould.

* Technical contribution to the 51st Rolling Seminar - Processes, Rolled and Coated Products, October $28^{\text {th }}$ to $31^{\text {st }}, 2014$, Foz do Iguaçu, PR, Brazil. 


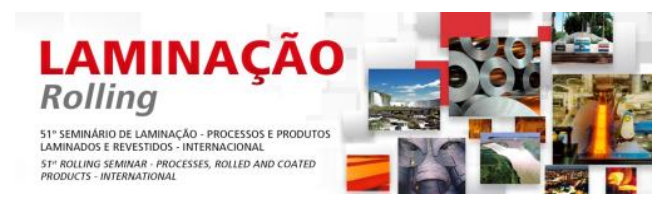

\subsection{Simulation of a High Temperature Heat Treatment Process}

This project was carried out in cooperation with the Institute of Material Science and Welding at the Technical University of Graz.

The first steps were made with a roll piece by collecting the data of the full heat treatment cycle from heating up over all steps of cooling and tempering. The important factor was to generate the temperature data in different depths of the roll, to get raw data about the possible temperature gradient in the roll during the cycle figure 7. The first version of the simulation programme with details added to the ANSYS software included the simple heat transfer and distribution in the roll. In a later stage the most important part for the stress calculation during the cycle was to create a model for the transformation induced plasticity (TRIP). A major part of the simulation programme which is so far never included in one of the standard simulation software packages.

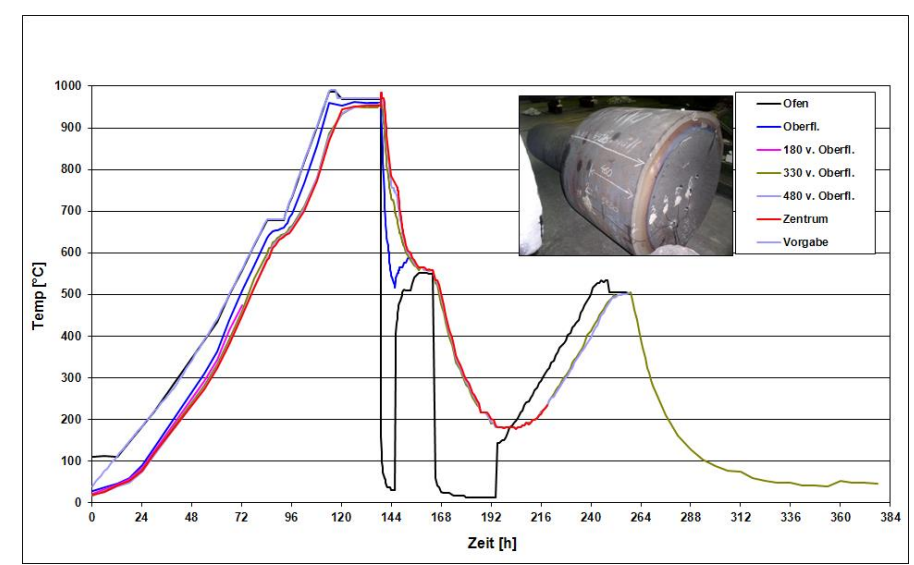

Figure 7: Record of Heat cycle with Roll piece

To get all the material data, more than 200 samples of shell and core have been taken and in a Gleeble machine the strength of the material under different temperatures was determined. The heat treatment parameters were observed by a thermal imaging camera as shown in Figure 8. In combination with thermocouple measures the different emission coefficients have been calculated and integrated.
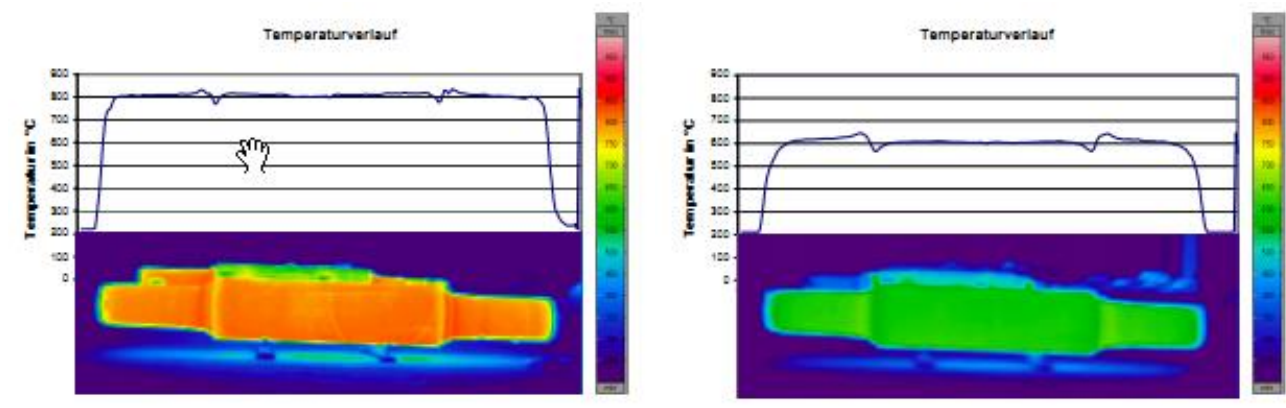

Figure 8: Thermal images at beginning and during cooling

The final result of this project was a high variation of different cycle types for 2 different material combinations. The knowledge of the stress evolution during the heat cycle could be understood much better. Now it is possible to adjust the principal heat curve just by running a few dilatometer curves. The application of a heat cycle

* Technical contribution to the $51^{\text {st }}$ Rolling Seminar - Processes, Rolled and Coated Products, October $28^{\text {th }}$ to $31^{\text {st }}$, 2014, Foz do Iguaçu, PR, Brazil. 


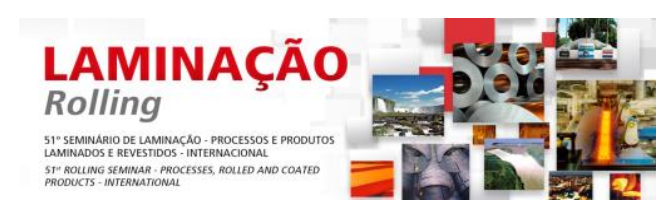

for new materials is now based on better understanding of the different stages of the heat treatment.

\section{SOME POSSIBLE FUTURE ROLL MATERIALS AND MANUFACTURING ROUTES}

\subsection{New Materials}

\subsubsection{Cemented Carbide}

At least when it comes to hot rolling of wide flat steel the use of Cemented Carbide rolls is at this point not known. Cemented Carbide rolls have been used for more than 20 years though in rolling of long products. Reported values of performance increases could sometimes range from 30-50 times.

\subsubsection{Ceramic systems}

Today the use of Ceramics as roll material is very limited due to the size requirements. The only material known to be used is SIALON and this is a man made Ceramic alloy.

\subsection{Alternative Production Methods}

There are at least 4 obvious reasons for introducing new or modified production technologies when it comes to roll production in order to increase the value in use:

1. Cost of production

2. Possibility to modify the structure in existing alloying systems

3. Possibility for new material combinations (compound rolls)

4. Possibility to introduce completely new materials and alloying systems In the following some examples will be given on some of the technologies that are at the edge of being used and also what might come in a longer perspective (10-15 years).

\subsubsection{Cladding technology}

The use of cladding technologies see figure 9 below one example from Japan offers compared to Spin Casting technology a somewhat higher cooling rate and thus some structure improvements are to be expected. In this technology the cooling rate during solidification is primarily controlled by induction technology (the heating system of the mould).

* Technical contribution to the $51^{\text {st }}$ Rolling Seminar - Processes, Rolled and Coated Products, October $28^{\text {th }}$ to $31^{\text {st }}, 2014$, Foz do Iguaçu, PR, Brazil. 

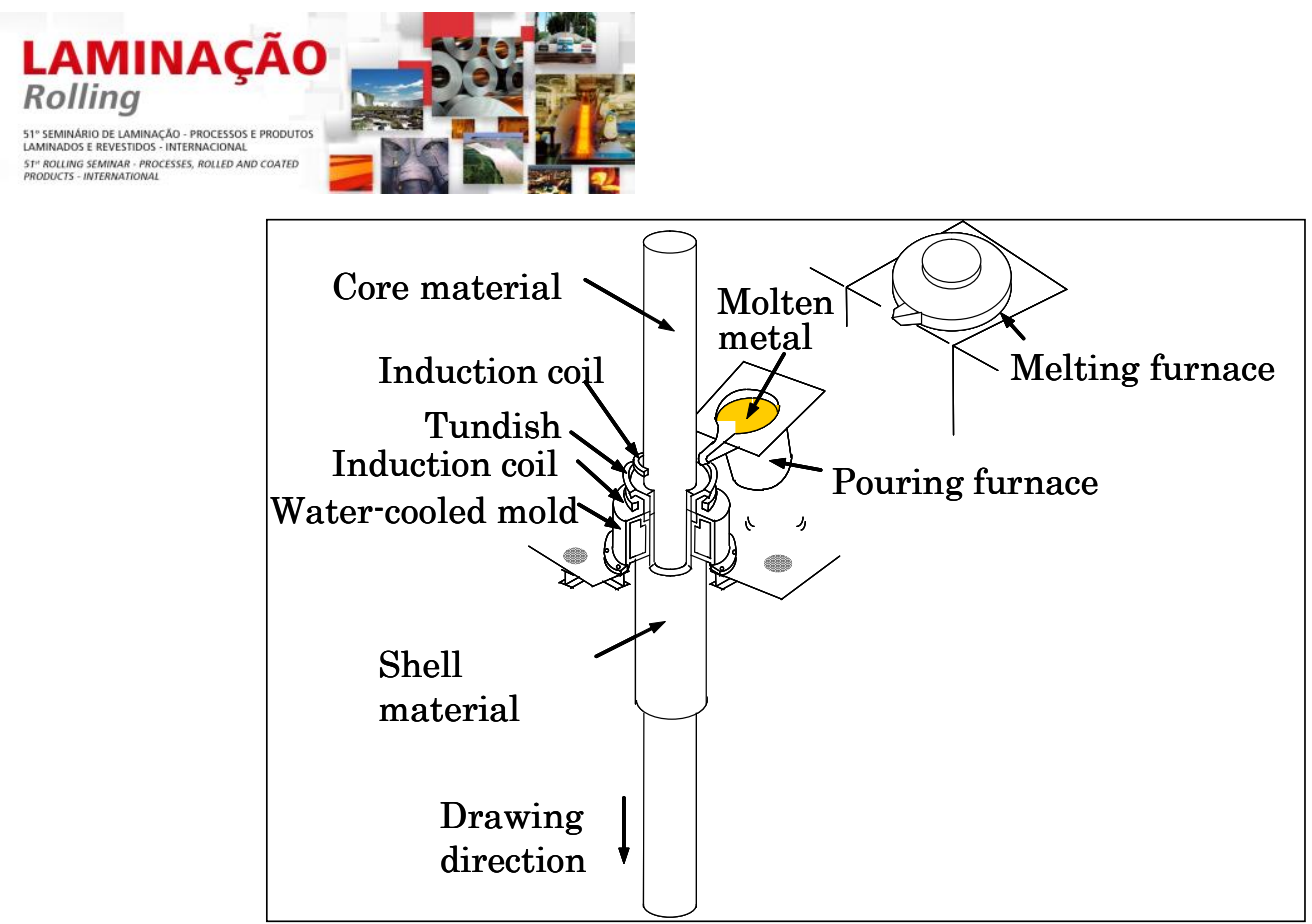

Figure 9. Example of a CPC installation [1]

\subsubsection{Powder Metallurgy}

The most efficient way to reduce carbide size is by using PM (Powder Metallurgy). The melt is atomized, see figure 10 below and solidified in the form of very small droplets (typically $\varnothing<500$ microns) giving a very high cooling rate during solidification.

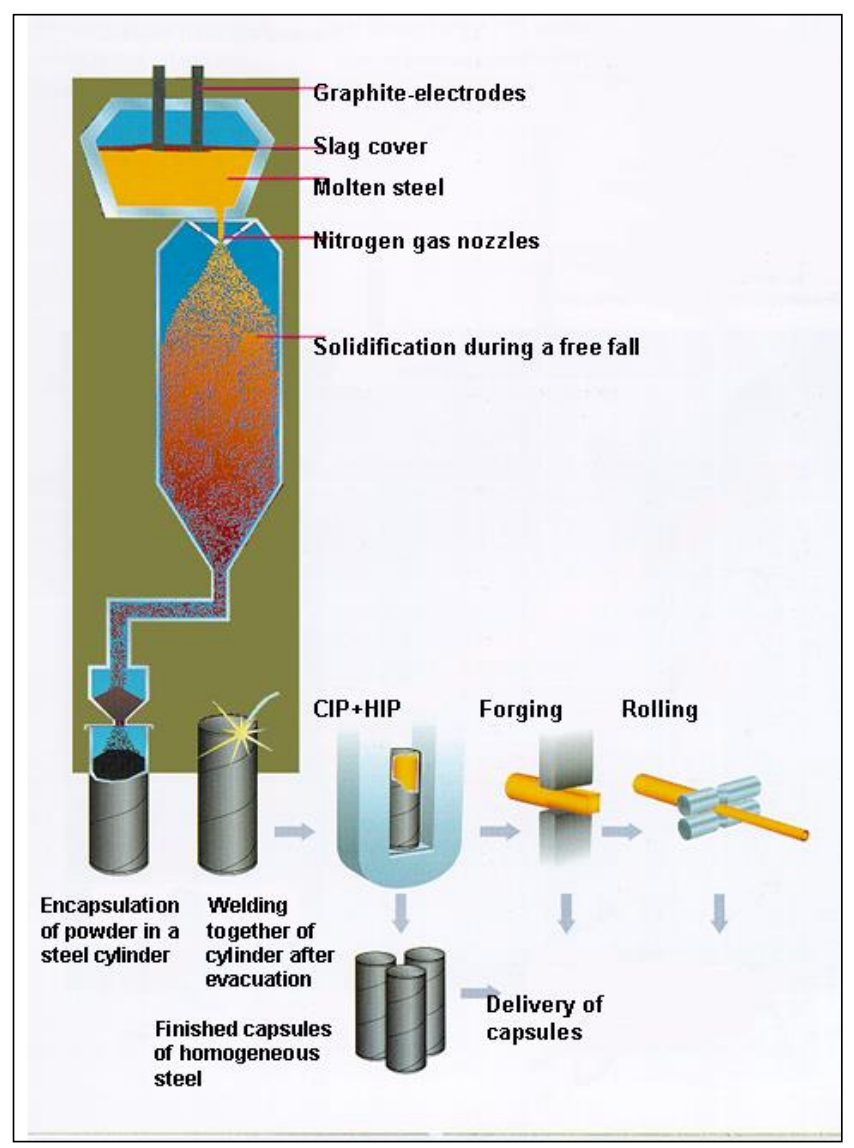

Figure 10. Erasteel PM production route [3]

* Technical contribution to the 51st Rolling Seminar - Processes, Rolled and Coated Products, October $28^{\text {th }}$ to $31^{\text {st }}, 2014$, Foz do Iguaçu, PR, Brazil. 

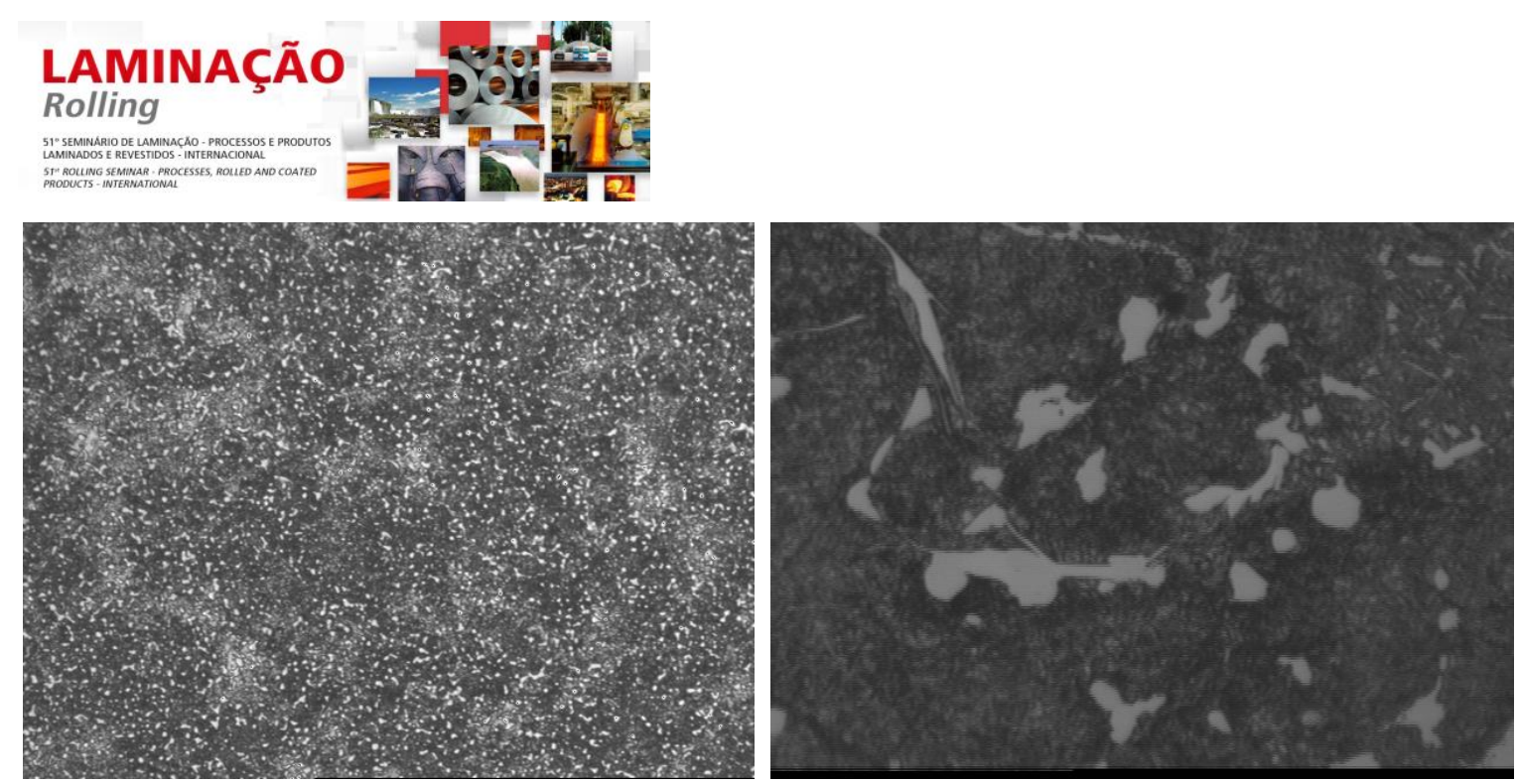

PM

\section{Spin casting}

Figure 11. HSS material produced by PM and Spin Casting (x500) [1].

\subsubsection{Spray forming}

Another technology based on the PM technology is Spray Forming that is producing in this case a monoblock material directly from molten droplets. This technology has the advantage of not demanding the hipping operation that is a costly operation. The process is shown in figure 12 below and also indicating some size limitation of the technology as of today.

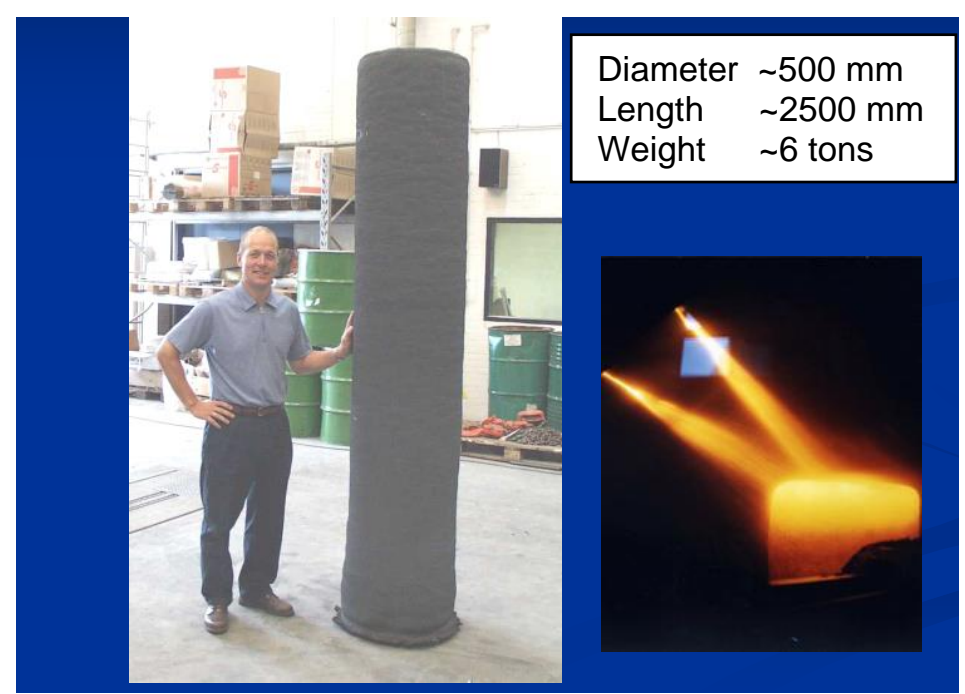

Figure 12. Sprayforming technology [2].

\section{CONCLUSION}

ESW is using a well defined and transparent R\&D process in combination with skilled technical staff and necessary R\&D equipment in close interaction with leading Universities and Technical Institutes. In addition we keep a close contact with our customers thus enabling us to be always reactive and proactive and to be regarded as one of the leading roll makers in the world.

ESW is constantly trying to be at the leading edge both in terms of roll material developments but also in general technical support to be considered as the total solution provider.

* Technical contribution to the $51^{\text {st }}$ Rolling Seminar - Processes, Rolled and Coated Products, October $28^{\text {th }}$ to $31^{\text {st }}, 2014$, Foz do Iguaçu, PR, Brazil. 


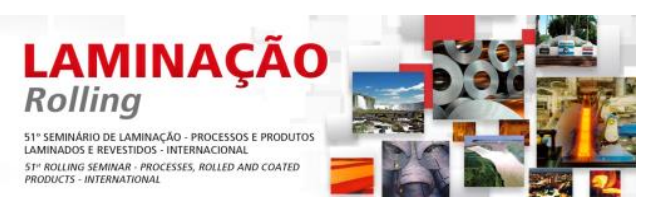

\section{REFERENCES}

1 Nylén T. The R\&D Process And The R\&D System as Performed By Eisenwerk Sulzau Werfen, $48^{\text {th }}$ ABM Rolling Seminar 2011

2 Nylen T. Present and future roll making technologies. Rolling seminar Valsverksföreningen, Borlänge, Sweden 2005, 1CD.

3 Erasteel company web site, www.erasteel.com.

* Technical contribution to the $51^{\text {st }}$ Rolling Seminar - Processes, Rolled and Coated Products, October $28^{\text {th }}$ to $31^{\text {st }}, 2014$, Foz do Iguaçu, PR, Brazil. 